\title{
Second-language Proficiency and Exposure to Work Environments-Their Impact on Pragmalinguistic Knowledge of Implicature
}

\author{
Nashid Nigar \\ Department of Linguistics \& Applied Linguistics, School of Languages \& Linguistics, The University of Melbourne, \\ Australia
}

\begin{abstract}
L2) proficiency and exposure to work environments influence language learners' pragmalinguistic knowledge of implicatures, I surveyed 76 native and non-native participants in Australia. Thirty non-native respondents were from working contexts and 31 from tertiary education institutes, and 15 native speakers were drawn from a university context. Analysis revealed no working context effect on understanding of implicature items but substantial L2 proficiency effect, and some length of residence effect on pragmatic knowledge of implicature. I concluded that formulaic implicature is more difficult to understand than idiosyncratic implicature in which the conversation's principles are violated. This study has potential implications for policy making in the areas of Australian language, curriculum development, pedagogical approaches, and English teacher professional development and standardisations.
\end{abstract}

Index Terms—implicature, pragmatics, sociolinguistics, EAL, ESL, non-native English speakers

\section{INTRODUCTION}

Many English as an Additional Language (EAL) learners struggle to comprehend and use the English language's pragmatic components in classrooms or real-life encounters. This is true even for advanced learners, who may still lack pragmalinguistic and sociolinguistic knowledge and have language proficiency that far exceeds their pragmatic knowledge (Bardovi-Harlig \& Dörnyei, 1998; Bardovi-Harlig \& Hartford, 1990, 1993), possibly due to insufficient natural pragmatic input in the classroom (Bardovi-Harlig \& Hartford, 1996; Kasper, 1997).

This study was designed to examine the performance of implicatures of non-native speakers of English (ENNS) in relation to their language learning and workplace contexts. I sought to investigate whether advanced L2 learners have less pragmatic knowledge of implicature than advanced ENNS working in Australia or vice versa. I also aimed to examine whether the formulaic implicature which follows a routinised pattern in conversations is more difficult to understand than idiosyncratic implicature, in which the Grecian conversation's maxims are violated (Grice, 1975). As in previous research (Bouton, 1999; Röver, 2005b; Taguchi, 2005), I studied the relative impact of exposure and proficiency on comprehension of implicature across contextual variance. I also examined the impact of length of stay and degree of communication with English Native Speakers (ENSs) outside work or study on understanding of implicature.

The outcomes of the study indicate the need to adapt necessary work placements in EAL courses in Australia. They also suggest the need to conduct further research on the implicature items used in various contexts and the possibility of introducing them into Australian EAL curricula design. In the following sections I review previous works on interlanguage pragmatics, outline the research questions, methodology and results, and discuss the significance of the main outcomes.

\section{LITERATURE REVIEW}

\section{A. Pragmatics}

Pragmatics are concerned with how the transmission of meaning relates not only to the linguistic knowledge (e.g., grammar, lexicon) of the interactants, but also to the context, the speakers' previous experience and knowledge about interlocutors' status, inferred intent and so on. Grice (1975) proposed that in ordinary conversation, certain cooperative principles, in which the interlocutors cooperate to achieve mutual conversational ends, help shape understanding of utterances. According to Kasper (1997), to be pragmatically competent, one has to comprehend and produce a communicative act. This often requires knowledge of social cultures, the norms of the relevant speakers and covert and overt linguistic knowledge. Consequently, pragmatics help understanding of the implicit message.

\section{B. Interlanguage Pragmatics}

Within the second language acquisition (SLA) domain, pragmatics is referred to as interlanguage pragmatics (ILP) (Kasper \& Rose, 2002). ILP studies the continuum of L2 learners' development of knowledge about how the language 
is practised according to its appropriate sociopragmatic and pragmalingusitic norms. It incorporates L2 pragmatic development, its use, production and comprehensions as well as instructed learning and assessment (Niezgoda \& Röver; 2001; Bouton, 1988, 1994a, 1999; Taguchi, 2007; Yamanaka; 2003; Cook \& Liddicoat, 2002;). Many factors affect the development of ILP knowledge, such as environment, proficiency level, quality of input, overgeneralisation, simplification, aptitude, motivation and other individual differences, degree of interaction with ENSs, field of occupation or study, and amount of television viewing (Röver, 2005; Schmidt, 2001; Yamanaka, 2003). Leech (1983) and Thomas (1983) divided pragmatics into pragmalinguistics and sociopragmatics. Both components refer to the skills and strategies for conveying communicative acts and interpersonal meanings within the frame of social perceptions which underpin participants' interpretation and performance of communicative action. Being sociopragmatically competent means knowing the social conventions for "what you do, when and to whom" (Kasper \& Röver, 2005, p. 2), particularly perceptions of relative power, social distance, and degree of imposition (Brown \& Levinson, 1987). Pragmalingusitic competence encompasses knowledge of conventions of means (strategies for realising speech intentions) and conventions of forms (linguistic items used to express these intentions) (Kasper \& Röver, 2005). For instance, implicature is a linguistic strategy (convention of means) for conveying an implicit or indirect message/meaning in English, but the linguistics items (conventions of forms) used to perform this strategy can be formulaic implicatures such as indirect criticism or irony. Both types of knowledge enable L2 learners to correctly appropriate pragmalinguistic tools into sociolinguistic norms. In the ILP continuum, pragmalinguistic and sociolinguistic competence are not always comparable; learners can be more sociopragmatically than pragmalinguistically competent or vice versa (Niezgoda \& Röver, 2001).

Most pragmatic research has concerned speech acts, such as greeting, request, apology, refusal, complaint, invitation (e.g., Omar, 1991; Hassall, 1997; Trosborg, 1995). Some work relates to situational routines (Kasper \& Röver, 2005; Kanagy \& Igarashi, 1997), but few studies, thus far, have targeted conversational implicature-inferences that can be drawn from an utterance by examining its conformity to the canons of normal conversation and its pragmatic function within the situation (Bouton, 1999; Taguchi, 2007; Yamanaka, 2003).

Over the past two decades, researchers have examined ILP comprehension and development at different proficiency levels and how this correlates with overall L2 proficiency. Rose (2009) compared 98 Hong Kong primary school children's apologies, requests, and compliment responses. In the case of requests, conventional indirectness and supportive moves increased with increasing English proficiency. Rose found that English as a Second Language (ESL) proficiency was the major factor in pragmalinguistics performance, and that students' ESL pragmalinguistic knowledge was ahead of their sociopragmatic knowledge. Trosborg (1995) found Danish learners of English with increased proficiency used near native-like request strategies. Hill (1997) examined request strategies used by Japanese English as a Foreign Language (EFL) learners at three proficiency levels; with increasing proficiency, they used fewer direct request strategies and used conventionally indirect requests almost at an ENS level. Taguchi (2007) found that highly proficient learners produced utterances faster and more accurately and were better - than those with lower proficiency levels - at comprehending non-conventional implicature (Taguchi, 2008b, 2011).

Exposure also plays an important role in learners' pragmatic knowledge. It includes length of residence, interaction with ENSs with whom socialisation occurs, having an ENS partner, learning opportunities in or outside the classroom, and language settings (Kasper \& Rose, 2002). Numerous studies have targeted the function of environment in pragmatic competence development. Matsumura (2001) examined Japanese ESL and EFL learners' perceptions of interlocutor social status and found an exposure effect for ESL learners. To her, high-contact learners were more target-like in judgements of appropriateness (Matsumura, 2003). High exposure is also helpful to adapt speech-act realisation to social situations (Shivey, 2011). Highly exposed groups know culturally accepted ways of talking about everyday matters, such as the weather or food (Dufon, 2006). Some researchers regard exposure as the most important factor in knowledge of routines, and view proficiency as negligible (Osuka, 2017; Röver, 2011). Bardovi-Harlig and Dörnyei (1998) found that ESL learners had greater pragmatic than grammatical awareness, whereas EFL learners had greater grammatical than pragmatic awareness. These findings indicate that residency in the target language environment means greater contact, more input, more gap awareness, and more motivation to acquire pragmatic competence for ESL than for EFL learners (Schmidt, 2001). Niezgoda and Röver (2001) replicated Bardovi-Harlig and Dörnyei’s (1998) finding that ESL learners rated pragmatic errors as significantly more severe than grammatical errors, except in the case of the highly motivated EFL group. In addition, various researchers have shown that length of stay in the acquired speech community affects the pragmatic competence of ENNS (Bouton, 1994b; Olshtain \& Blum-Kulka, 1985; Yamashita, 1996).

\section{Implicature Studies}

Pragmatic comprehension refers to the ability to understand implied speaker intention using linguistic knowledge, contextual clues, and the assumption of relevance (Horn \& Ward, 2008). Contextual clues can be drawn from the immediate or the larger socio-cultural context (Sperber \& Wilson, 1995). For instance:

A: Will Sally be at the meeting?

B: Her car broke down.

$+>$ Sally will not be at the meeting. 
Here, speaker B assumes that the cooperative principles are in operation and A is not purposefully saying something irrelevant or not paying attention to her, deducing that Sally will miss the meeting because her car broke down and she cannot come to work. Understanding this kind of implicature requires minimal contextual knowledge, but some instances require considerable background knowledge. For example, if A asks B to go to shopping centre X after 5 pm, B might respond: "It's Monday". To decipher this implicature, speaker A has to activate her background knowledge about shopping hours and recall that shops close at $5 \mathrm{pm}$ at shopping centre $\mathrm{X}$ on Mondays. This kind of implicature is not universally possible. It makes sense to someone who is aware that shops usually close at 5 pm on Mondays at that particular shopping centre, but would be much more perplexing to someone who is not aware of the shopping centre opening hours on different days. Implicatures can be "based on knowledge specific to the speaker and hearer in terms of their shared history or shared knowledge about other aspects of the world, academic field, work experience, sporting interest" (Röver, 2013, p. 44).

Horne and Ward (2008) posited that "what a speaker intends to communicate is characteristically far richer than what she directly expresses" (p. 3), but the communicated linguistic meaning may undermine the message implied and understood. Accordingly, implicature, an indispensable pragmalinguistic constituent, has become one of the principal subjects of pragmatics in the interlanguage field. The theory of implicatures is attributed to Grice (1975), who observed that the cooperative principles - quantity (provide the exact amount of information needed), quality (give true information), relevance, and manner (be clear and concise) - are not always observed, resulting in implicatures. Implicature denotes the act of meaning, implying, or suggesting one thing by saying something else, or the object of that act. Implicatures can be part of sentence meaning or dependent on context and can be conventional (in different senses) or unconventional; the speaker expresses attitudes and feelings using indirect utterances that must be inferred by the hearer (Grice, 1975; Sperber \& Wilson, 1995). In order to comprehend implicatures, the hearer infers the speaker's attitudes or feelings. Communication is never achieved by the mere decoding of linguistic stimuli; communication includes interpreting contextual clues and using them as evidence towards the correct inferencing of speaker intentions.

The fundamental types of implicature are conventional and conversational implicature. Conventional implicature is semantic, generated by the meaning of words in the sentence structure. It is not based on the cooperative principles and is not conversation and context dependent. Conversational implicatures are:

a) calculable (listeners must be capable of working out the implicature for themselves; otherwise it would be a conventional implicature);

b) cancellable (can be denied explicitly); and

c) nondetachable (the implicature would remain the same even if the speaker said nothing else).

Conversational implicature can be general (idiosyncratic, in Bouton's terms) or specific (formulaic) implicature which follows a routinised schema (Bouton, 1994a), as in the case of the Pope Question ("Is the Pope Catholic?") and indirect criticism that focuses on a minor aspect (“Is the food good?"-“Let's just say it's colourful”).

As evident in the literature reviewed above, some ILP studies have addressed implicature alone or in conjunction with other pragmalinguistic components (e.g., Bouton, 1988, 1999; Garcia, 2004; Röver, 2005, 2006; Yamanaka, 2003; Taguchi, 2007, 2008). They have addressed developmental and teachability aspects of conversational implicature in terms of production and comprehension. Those cited above addressed variables in the EAL environment, such as EAL settings, length of stay in the EAL milieu, and degree of interaction with ENNS, in relation to the development of conversational implicature. Rose and Kasper (2002) argued that studies focusing on comprehension are poorly represented within the L2 developmental pragmatic literature.

Taguchi (2002) analysed the ability of two proficiency levels of L2 learners in Japan to comprehend conversational implicature, finding that both groups comprehended $70 \%$ of the items using the same kind of inferential processes, because "inferential abilities could be part of general human cognition, and can be transferred to L2 comprehension and guide utterance interpretation" (p. 169). She observed a significant difference in the accuracy of implicature interpretation between the proficiency levels, but learners were still able to relate the speaker's implied meaning to the relevant context. Taguchi (2002) argued that "paralinguistic cues and the rule of adjacency pair were common inferencing strategies. Less proficient learners relied more on background knowledge and key word inferencing" (p. 151). Proficient learners more frequently identified the intended purpose of using implicature.

Taguchi (2005) stated that pragmatic comprehension, namely the ability to comprehend implied meaning in spoken dialogues, is influenced by L2 proficiency in a foreign language context. She also investigated how different types of implied meaning affected accuracy and speed in understanding implicature. The participants found formulaic implicature more difficult than idiosyncratic implicature; ENSs responded more accurately, quickly, and consistently to the implicature items than ENNSs. Taguchi (2007) also performed an L2 implicature study, finding a significant correlation between lexical access speed and the response speed of pragmatic comprehension as well as between general language proficiency level and accuracy of pragmatic comprehension.

Bouton (1988, 1992 1994a, 1994b) studied the advanced ESL learner's ability to interpret conversational implicature. A 33-item multiple-choice test was used to measure learners' pragmatic knowledge of implicature, first within a standard ESL placement test which was re-administered 17 and 33 months later. Bouton also tested another ESL group that had been on campus for 4-7 years and an ENS comparison group. ESL students scored far lower on formulaic implicature than on idiosyncratic implicature, but over time, the students scored considerably higher on both implicature 
types; their proficiency at idiosyncratic implicature almost matched ENS levels (97.7\%) without any instructions. Bouton (1994) reported that even though ENSs' and ENNSs' scores differed significantly, the difference lessened greatly with length of residence. However, "irony" implicature remained problematic for ENNS participants (Bouton, 1999).

Bouton (1999) found that formulaic implicature was easy to teach but idiosyncratic implicature was not, which was due to ESL learners' considerable exposure to idiosyncratic implicature in everyday discourse, while formulaic implicature hardly featured. The participants' proficiency and scores on the implicature test were uncorrelated, but Bouton did not compare the exposed group with the unexposed ESL and EFL groups (Röver \& McNamara, 2006). Bouton's learner population consisted of learners in L2 settings but not in first language (L1) settings. In contrast, Röver (2005a, 2006) included L2 learner populations from both settings. Röver (2006) argued that perhaps Bouton's learners' English proficiency increased with prolonged stay in the L2 setting, so the effect was due to proficiency rather than to exposure.

Yamanaka (2003) found that L2 proficiency and length of residence in the target language environment influenced comprehension of implied meanings and the ability to make inferences. Furthermore, Röver (2005, 2013) showed that only increased L2 proficiency could improve deduction of implicature measures. Thus, because it is a pragmalinguistic component, knowledge of implicature is not affected by social context. Implicature is proficiency-dependent because learners must have sufficient proficiency to recognise an implicature. In line with Röver's findings, Taguchi (2002, 2005, 2007) found L2 proficiency influenced the accuracy of the implicature test significantly, attributing this to more accurate pragmatic comprehension. Hypothetically, as proficiency develops, learners acquire a way to control shortterm memory, directing their attention to the most relevant information and retaining the gist, thereby improving comprehension. This could be further tested in learning and working contexts in EAL settings with implicature test scenarios designed as typical workplace conversations. The result of such tests may build on the previous research as to whether proficiency or exposure is responsible for the comprehension of implicatures in everyday conversations.

In Röver's implicature test study (2013) for a diagnostic placement test, L2 learners scored significantly lower than ENSs, who exceeded $90 \%$ on all tasks other than indirect criticism. Röver confirmed that high proficiency is beneficial for implicature comprehension because it helps to identify when the conversational maxim is being flouted, yet formulaic indirect criticism items can be developed with exposure, especially contact and socialisation into target community norms. The ENNSs with more than a year's exposure did significantly better on formulaic indirect criticism items than those with less exposure, because exposure shows learners what is culturally accepted and what is not. Unlike Bouton (1999), Röver (2013) showed that advanced learners learn how to interpret formulaic indirect criticism through socialisation.

In summary, few studies so far have addressed conversational implicature in the ESL context. Moreover, no study thus far has investigated whether exposure to different contexts in an ESL setting and level of English mastery in L2 settings are responsible for L2 learners' performance on implicature.

\section{Aims and Research Questions}

I sought to determine if learning or working contexts in the ESL setting affect conversational implicature for advanced learners, and the comparative influence of exposure and proficiency on its comprehension. Secondly, I aimed to identify whether ENSs performed better than ENNSs at conversational implicature (Bouton, 1988, 1994b, 1999). Thirdly, I examined whether some implicature types are more difficult, which would imply that lessons can be planned around idiosyncratic or formulaic implicature. The specific research questions (RQs) were:

1. ENSs perform differently to ENNS groups on the implicature test questionnaire if implicature items are signed based on work contexts?

2. Do participants in learning contexts or working contexts perform better on the implicature questionnaires when those are contextualised?

3. What is the relative impact of exposure and proficiency on the comprehension of implicature?

Is formulaic implicature more difficult to understand than idiosyncratic implicature?

\section{METHODOLOGY}

\section{A. Participants}

A total of 76 participants took part in this study, consisting of ENS and ENNS participants in educational as well as work settings. The volunteer male and female participants' ages ranged from 18 to 70 . A comparison group of 15 female participants of a wide range of ages who were ENSs in Australia and New Zealand at a university College of Education in Victoria was included in the study. Recruiting the ENS participants assisted in establishing a benchmark to decide the ENNS participants' performance on the implicature questions. 
TABLE 1.

THREE GROUPS OF PARTICIPANTS

\begin{tabular}{ccc}
\hline Groups & Numbers & \% \\
\hline NS & 15 & 19.736 \\
WP & 31 & 40.789 \\
CL & 30 & 39.473 \\
Total & 76 & 100 \\
\hline Note: NS = Native speakers, WP = Working place; CL = Learning context
\end{tabular}

Note: $\mathrm{NS}=$ Native speakers, $\mathrm{WP}=$ Working place $\mathrm{CL}=$ Learning context

The rest of the 61 volunteers were employed in ENNS educational institutions and workplaces. The 61 participants consisted of participants from working (WP) and learning (CL) contexts. Among them, 37 were female and 24 were male. The 30 EAL advanced learner participants were situated in different EAL courses and mainstream courses and were either Australian refugees, immigrants or aspirant immigrants, as well as some international students who were from different L1 backgrounds, namely Asia, Africa, Europe and South America. Most of the participants were from the Certificate IV in EAL Further Studies course and some were higher education students from different disciplines. The majority of the EAL Further Study students were professionals from various disciplines in their home countries. They were pursuing the given course to develop their academic English, either as a pathway to higher education or to find jobs in their own fields. Most of them were holders of Diplomas or Bachelor or post-graduate degrees. The participants, other than those in EAL Further Studies, were from mainstream higher education courses. The 30 EAL participants in work contexts were drawn from various workplaces in Melbourne, namely private SME companies, government departments, educational institutions, and the like.

A pilot study of 10 to 15 participants was conducted before venturing into the main project to justify the validity and feasibility of the prospective study. The participants' L2 proficiency levels were at advanced levels, with IELTS band scores ranging from 5.5 to 8.00 .

Although a total number of 76 participants took part in this study, 15 native speaker participants did not need to respond to the background questionnaire. Consequently, the background information for only the two groups of nonnative speakers is reported, representing $81.3 \%$ of the total participants. This included $50.8 \%$ workplace related participants and $49.1 \%$ learning context related participants.

\section{B. Instruments}

The ENNS participants were asked to complete a background questionnaire, a proficiency cloze test, and a test of implicature; the ENS participants were not given the background questionnaire. The implicature test included an instruction page for participants' reference; instructions for the background questionnaire and proficiency cloze test were given orally.

1. Background questionnaire

Participants were requested to supply short answers to questions about their socio-demographic, study, work, socialisation and entertainment-related characteristics. The questionnaire asked about country of birth, first language and educational backgrounds, age, gender, employment, contexts of English use, socialising contexts, length of study, and length of stay in Australia. It also asked if they used implied meaning in the first language, if they were taught implied meanings, and whether they had an English-speaking partner.

2. Proficiency C-test

The C-test was conducted to identify the participants' proficiency levels. For decades, c-tests have been successfully used to test ESL proficiency, and it is now deemed to be a very useful device for measuring ESL proficiency (Oiler\& Conrad, 1971). Aitken (1977) believes that "cloze tests are valid, reliable second language proficiency tests" (p. 59)

3. Implicature test

I devised a 20-item multiple-choice questionnaire to assess the participants' pragmatic knowledge of formulaic and idiosyncratic implicature. Some items were modified versions of a web-based test of an ESL pragmalinguistics instrument (Rover, 2005). Before administration, five of my ENSs colleagues (not research participants) reviewed the test items and judged them to be natural and plausible. The questionnaire presented 20 workplace-related implicature scenarios and four response choices for each; 13 scenarios were idiosyncratic (seven immediate situational context items, five larger socio-cultural context items and one scalar item) and seven were formulaic (three types: two items referred to irony, three to indirect criticism and two were Pope Qs).

Most research on implicature has employed multiple-choice questionnaires (e.g., Bouton, 1992, 1999; Murray, 2011; Kasper \& Röver, 2005; Röver, 2005, 2006; Yamanaka, 2003). Röver's (2000) web-based ESL pragmalinguistic instrument has been shown to be reliable and valid (Röver, 2006); however, it is not a listening test, so the learners' real-time processing effect cannot be reflected.

\section{Procedures}

Using the three instruments, a pilot study of 15 participants from both settings was conducted to determine the validity and feasibility of the study. The test result showed no significant difference between the two groups in terms of the comprehension of implicatures used in Australian context. 
Participants took 30-60 minutes to complete the tests. The multiple-choice implicature questionnaire for the EAL learning context participants was administered in classrooms at multiple campuses of a Victorian university in the presence of the researcher and the course lecturer. Some completed questionnaires from the workplace ESL participants were emailed to the researcher. The data in EAL work contexts were collected by the researcher either face-to-face or via email, or by volunteers at workplaces. For the test in the EAL work contexts, the questionnaire was emailed to participants. The ENS participants took the C-test and the implicature test in a classroom setting at a Victorian university.

The implicature test and the C-test were scored manually, and the scores and the background questionnaire responses were manually entered into Microsoft Excel. All section scores for the implicature test were computed as percentages.

The data were analysed in Microsoft Excel and SPSS v.18. I performed statistical analyses to answer the research questions. Research question 1 was investigated using one-way analysis of variance (ANOVA) for multiple comparisons between three groups (ENS, WP ENNS and CL ENNS). As the Levene test of homogeneity of variance is significant, Tamhane post hoc test were performed to quantify and examine the exact significance of differences in performances of three groups of participants on the implicature questionnaire. For the second and third questions, independent t-tests were carried out. A paired sample dependent t-test was performed for the last question, along with more descriptive analyses in Microsoft Excel.

\section{RESUlts}

\section{A. Participant Descriptions}

Sixty-one ENNS participants were recruited from ENNS educational institutions and workplaces in Australia and New Zealand, and 15 female ENS from a university in Victoria, Australia-in all, 52 women and 24 men, aged 18-70 years. The EAL advanced learner participants were refugees, immigrants or aspirant immigrants, and international students from Asia, Africa, Europe and South America. Most participants had been professionals in their home countries, and sought to develop their academic English for higher education or employment purposes. Most had diplomas, undergraduate or postgraduate qualifications. The EAL participants in work contexts were drawn from various workplaces in Melbourne-private companies, government departments and educational institutions.

Additional background information for the ENNS (81\% of all participants) is reported below (the 15 ENS were not asked to complete the background questionnaire). Few of the 61 ENNS participants (7\%) had English-speaking partners. Nearly three quarters (74\%) had been living in Australia for 1-10 years and 20\% for over 10 years. Almost all participants $(85 \%)$ were Asian.

A large number of workplace ENNS participants (31\%) were working in sales, management, as consultants, or in customer service and administration; smaller proportions worked in teaching and accountancy (10\%) and nursing/aged care $(8 \%)$. Almost half of the ENNS participants were employed full time. ENNS participants in learning contexts were undertaking a Certificate IV in EAL Further Studies (47\%), non-specified certificates, diplomas or bachelor studies (33\%), or postgraduate study (19\%). Most participants (54\%) had studied English for over 10 years before arriving in Australia, and $34 \%$ for less than five years.

More than a quarter of the ENNS participants socialised in English in local communities and religious institutions, on average more than three times per week, and over half (58\%) of their socialisation took place in English. However, 19 of the 51 who responded (31\%) did not socialise with native speakers at all. Two thirds of the participants used English for entertainment purposes, on average for 16 hours per week.

\section{B. Results of Analysis: Research Questions}

Research question 1: Do ENSs of Australian English perform differently than ENNS groups on the implicature test questionnaire if implicature items are designed based on work contexts? (Bouton, 1988; Taguchi, 2005; 2007) 


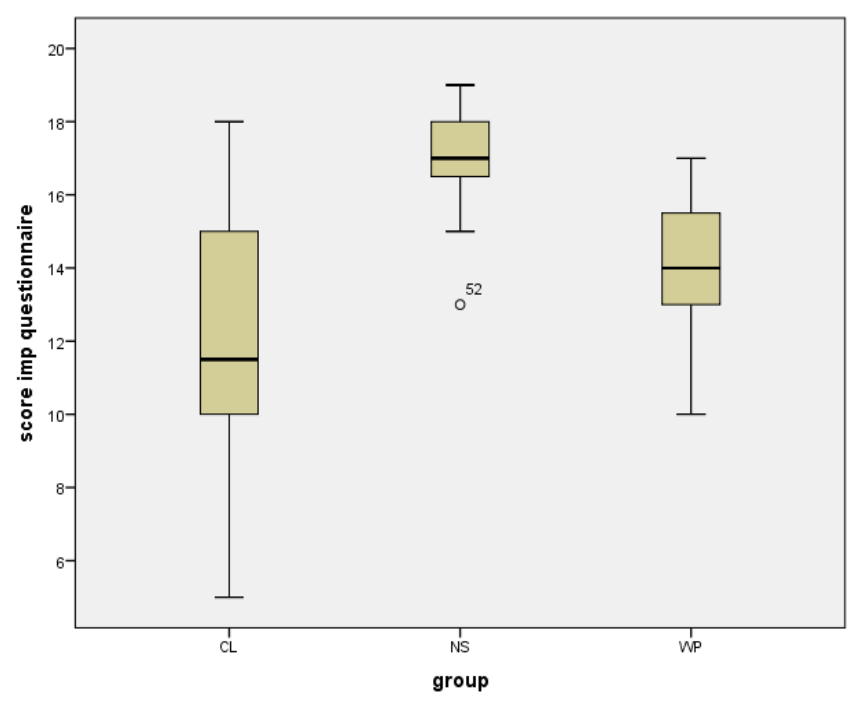

Figure 1. Inter-group Implicature Test Scores Histogram

To answer RQ1, I performed a one-way ANOVA of the implicature test scores for the ENS, CL and WP groups. The results are shown in Table 2 , and the results of post hoc tests for paired differences in Table 3.

TABLE 2.

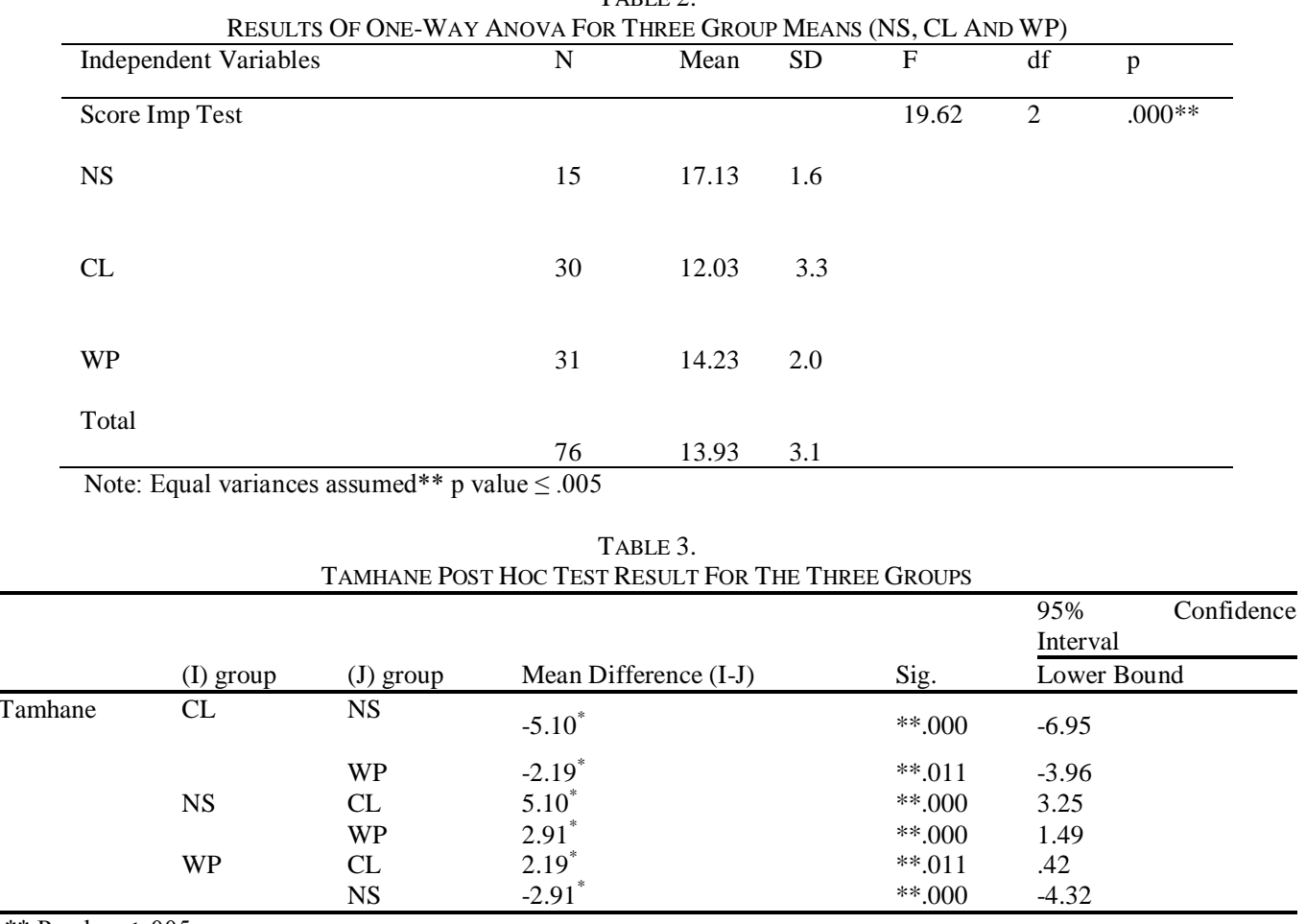

Consistent with previous studies (Bouton 1994, 1999; Röver, 2005, 2006, 2013; Taguchi, 2005, 2007, 2008b; Yamanaka, 2003), the present study found that the ENS group performed best on the implicature test, with the WP group second and the LC group third. Tables 2 and 3 show that the groups' mean scores differed significantly.

To answer RQ2, I ran t-tests to compare the WP and CL groups' implicature scores and their C-test scores. The results are shown in Table 4. 
TABLE 4

RESUlTS OF T-TEST FOR TWO GROUP MEANS (WP \& CL)

\begin{tabular}{|c|c|c|c|c|c|c|}
\hline Independent Variables & $\mathbf{N}$ & Mean & SD & $\mathbf{t}$ & df & $\mathbf{p}$ \\
\hline Score Imp QS & & & & 3.085 & 59 & $* * .003$ \\
\hline $\mathrm{CL}$ & 30 & 12.03 & 3.347 & & & \\
\hline WP & 31 & 14.23 & 2.077 & & & \\
\hline Score C-test & & & & 5.536 & 59 & $* * .000$ \\
\hline $\mathrm{CL}$ & 30 & 13.30 & 2.409 & & & \\
\hline WP & 31 & 16.90 & 2.663 & & & \\
\hline
\end{tabular}

Note: Equal variances assumed $* * \mathrm{P}$ value $\leq .005$

Table 4 shows that mean implicature test scores, and mean C-test scores, differed significantly between the two ENNS groups. The WP group scored higher in both cases.

To answer RQ3, I used univariate analysis of variance to assess the impact of exposure and proficiency on the comprehension of implicature. The results are shown in Table 5.

TABLE 5.

IMPACT OF EXPOSURE AND PROFICIENCY ON IMPLICATURE KNOWLEDGE

\begin{tabular}{lllll}
\hline Source & $\mathrm{df}$ & $\mathrm{F}$ & Sig. & Partial Eta Squared \\
\hline Corrected Model & 3 & 12.744 & $<.001$ & .406 \\
Intercept & 1 & 4.655 & .035 & .077 \\
Exposure (length of stay) & 1 & 5.782 & .020 & .094 \\
Proficiency (C-test score) & 1 & 19.345 & .000 & .257 \\
Group & 1 & .564 & .456 & .010 \\
Error & 56 & & & \\
Total & 60 & & & \\
Corrected Total & 59 & &
\end{tabular}

Table 5 reveals a significant difference between both scores of the two groups. The univarite analysis of variances in Table 5 shows that there is a significant difference between the C-test scores of the two groups $(P<.001)$ and the effect size is very high, at $25.7 \%$, but there is a negligible effect of residence for the given scores, at $9.4 \%$. These results suggest that proficiency has greater influence on ability to comprehend implied meanings than length of stay.

To answer RQ4, I performed paired sample t-tests on scores for formulaic implicature and idiosyncratic implicature test items for the CL and WP groups separately and as a whole. Results are shown in Tables 6-8.

TABLE 6.

COMPARISON OF IDIOSYNCRATIC AND FORMULAIC IMPLICATURE SCORES FOR THE COMBINED WP AND CL GROUPS

\begin{tabular}{|c|c|c|c|c|c|c|c|}
\hline Independent Variables & $\mathrm{N}$ & Mean & SD & $\mathrm{t}$ & df & Correlation & $\mathrm{p}$ \\
\hline Imp test score & & & & 9.49 & 60 & .58 & $<.001$ \\
\hline Pair 1 Mean_IDI & 61 & .71 & .13 & & & & \\
\hline Pair 1 Mean_FOR & 61 & .49 & .22 & & & & \\
\hline
\end{tabular}

Note: Equal variances assumed. IDI = Idiosyncratic, FOR = Formulaic, SD = standard deviation

TABLE 7.

COMPARISON OF IDIOSYNCRATIC AND FORMULAIC IMPLICATURE SCORES FOR THE CL GROUP

\begin{tabular}{lcccccc}
\multicolumn{6}{c}{ COMPARISON OF IDIOSYNCRATIC AND FORMULAIC IMPLICATURE SCORES FOR THE CL GROUP } \\
\hline Independent Variables & $\mathrm{n}$ & Mean & SD & $\mathrm{t}$ & $\mathrm{df}$ & correlation \\
& & & & & & \\
\hline Imp test score & 30 & .66 & .15 & & & .69 \\
Pair 1 Mean_IDI & 30 & .41 & .22 & & & \\
Pair 1 Mean_FOR & & .001 & \\
\hline
\end{tabular}

Note: Equal variances assumed. IDI = Idiosyncratic, FOR = Formulaic, SD = standard deviation

TABLE 8.

COMPARISON OF IDIOSYNCRATIC AND FORMULAIC IMPLICATURE SCORES FOR THE WP GROUP

\begin{tabular}{|c|c|c|c|c|c|c|c|}
\hline Independent Variables & $\mathrm{n}$ & Mean & SD & $\mathrm{t}$ & df & correlation & $\mathrm{p}$ \\
\hline Imp test score & & & & 5.531 & 30 & .305 & $<.001$ \\
\hline Pair 1 Mean_IDI & 31 & .75 & .11 & & & & \\
\hline Pair 1 Mean_FOR & 31 & .56 & .19 & & & & \\
\hline
\end{tabular}

Note: Equal variances assumed. IDI = Idiosyncratic, FOR = Formulaic, SD = standard deviation

Tables 6-8 show that the WP and CL groups, combined and separately, had significantly higher mean idiosyncratic than formulaic implicature scores, consistent with previous studies (Bouton, 1994, 1999; Taguchi, 2005, 2007; Röver, 2005, 2006, 2013).

To understand the different varieties of idiosyncratic items and formulaic implicature items more comprehensively, I analysed scores for their three categories. The combined WP and CL groups found the larger socio-cultural context group the most difficult idiosyncratic implicature (mean score 0.59 ), followed by the scalar implicature (0.66) and the 
immediate situational context (0.80) groups. For formulaic implicature items, the irony group and indirect criticism group mean scores were similar ( 0.43 and 0.45 respectively), but these were lower than for the Pope Q group (0.62). The most difficult item was a formulaic implicature irony item (mean $=0.19)$ followed by an indirect criticism item (0.24). The easiest idiosyncratic items were Questions 2 and 6 from the situational context group (mean scores 1.00); the hardest item was from the socio-cultural context group (0.34). For the formulaic implicature items, the hardest was from the irony group, (0.20) and the easiest a Pope Q item (0.803).

The CL group's mean scores were 0.77 for the situational context group, 0.61 for the scalar group, and 0.54 for the socio-cultural context group. The easiest items were from the situational context group (1.00). For the formulaic implicature, the hardest item was an indirect criticism item (0.097) and the easiest item a Pope Q item (0.774).

The WP group's results paralleled those of the CL group, with implicature mean scores for the situational context group of 0.84 , the scalar group 0.70 and the larger socio-cultural context group 0.65 . The easiest items were from the situational context group (1.00), and the hardest item was from the socio-cultural context group (0.27). For the formulaic implicature, an irony item scored lowest (0.27), and a Pope Q item highest (0.68).

For the ENS group, the most difficult items were an indirect criticism item (0.53) and a Pope Q (0.4).

\section{DisCuSSION AND CONCLUSIONS}

I investigated pragmatic knowledge of formulaic and idiosyncratic implicature in two groups of highly proficient ENNS participants in two settings and compared their comprehension with that of ENSs. Four research questions addressed external and internal factors that might influence understanding of the main implicature types. Consistent with previous research (Röver, 2005, 2006; Taguchi, 2002, 2007, 2008; Yamanaka, 2003), my analysis revealed that comprehension of implicature is not affected by work contexts but by levels of proficiency and, to some extent, years of residence in the target country.

\section{A. Summary of Findings}

Native English speakers scored much higher than ENNS groups (WP and CL) in implicature interpretation, replicating previous studies (Bouton, 1994b, 1999; Röver, 2005, 2006; Taguchi, 2002, 2007, 2008; Yamanaka, 2003).

In investigating whether participants in learning or working contexts perform better on implicature questionnaires when the scenarios are based on work contexts, the WP group scored significantly higher than the LC group, but this was due to the participants' proficiency rather than to workplace exposure (Niezgoda \& Röver, 2001; Röver, 2005, 2006; Taguchi, 2002, 2007, 2008; Yamanaka, 2003). My findings accord with those of other studies that included participants from both EAL and EFL contexts, showing that proficiency is the main determinant of implicature comprehension. The reason for the WP group's mean test score being significantly higher than the LC group's might be the WP group's daily interactions in a work context. It is likely that exposure at work would improve their proficiency levels and hence their pragmatic knowledge. However, this finding does not endorse the findings of Bouton's (1999) work in which he claimed that exposure influenced his participants' implicature knowledge acquisition.

Proficiency is conducive to implicature comprehension because a proficient listener's low-stake deductive processing helps them identify the flouting of a conversational maxim, drawing on the immediate situational context, larger sociocultural context, and indirect criticism. Low-proficiency learners may have insufficient linguistic repertoire to understand the overtly stated meanings and identify the implicature sentences and the discord between the implied and stated meanings. Therefore, sufficient proficiency to understand linguistic items is vital to identification of the violation of Grician maxims and the deductive work of the implicatures (Röver, 2006).

Bouton (1999) found that, even after four and a half years of living in the target environment, his ENNS participants continued to have difficulty comprehending all kinds of formulaic implicature. Similarly, my findings suggest that length of residence in Australia had a small effect (Röever, 2013) on comprehending both idiosyncratic and formulaic implicatures (notably indirect criticism items). The more that learners are exposed to the target language environment, the more they acquire pragmatic knowledge. This helps them comprehend immediate situational context and sociocultural norms, such as when an indirect criticism is intended, enabling them to identify pragmalinguistic items. On the other hand, low-proficiency learners may not have enough linguistic repertoire to understand the overtly stated meanings, or to identify the implicature sentences and the discord between the implied and stated meanings.

This study shows that formulaic implicatures were substantially more difficult than idiosyncratic implicatures for both the WP and CL groups, in line with previous research (Bouton, 1994b, 1999; Taguchi, 2005, 2007; Röver, 2005, 2006, 2013; Yamanaka, 2003). Even though understanding formulaic implicature was difficult for the WP group, it was almost $20 \%$ more difficult for the CL group. It is generally easier to draw on immediate situational contexts to comprehend an idiosyncratic implicature, but in a formulaic implicature, if somebody is not aware of a given concept in the L2 culture, it is impossible to understand the intended meanings.

Both the CL and WP groups found the larger socio-cultural context group the most difficult of the three varieties of idiosyncratic implicatures. This was because socio-cultural implicatures require sufficient cultural and social knowledge in order to understand the implied meaning. The scalar idiosyncratic and immediate situation context implicatures were found to be relatively easy, as measurement of scales and immediate situations can universally be understood. In these instances, the listener must simply identify the maxim that has been flouted and relate the situation to the implied 
meaning. In contrast, the irony formulaic implicature type was the most difficult for both groups, and the indirect criticism type was almost as difficult. This is because irony conveys a meaning opposite to the words' literal meaning, and in indirect criticism, something else is meant than what is literally said. In both types, the meaning may be different to what is overtly stated. This requires the listener to undergo a complex process to comprehend the statement and a question is answered with another question which has the same meaning.

For the two EAL groups together and individually, the easiest items in the idiosyncratic implicature group were the ones requiring interpretation of overstated and understated statements according to the relevant situational context. The most difficult items in this category were from the larger socio-cultural group for all of the participants together. The reason for difficulties in deciphering these questions relate to the need for some socio-cultural knowledge (e.g. the weather is unlikely to be cold in January in Australia). However, in the formulaic implicature group, the hardest item was an irony item. The reason this was the participants' unfamiliarity with verbal irony in which there is a contradiction of expectation between what is said and what is really meant. Participants were unable to pick up on the incongruity between reality and appearance so that, although the performance appraisal meeting was a difficult one, many stated that it had gone well. Again, while answering the second most difficult formulaic implicature item, an indirect criticism (Question 4), the participants needed to have sufficient cultural knowledge to understand an aspect of Australian culture-that is, that describing food as "colourful" actually has a negative connotation, which it might not have in other cultures.

\section{B. Limitations and Future Work}

One of the main limitations of my study was that the collected data may not represent natural situations, and hence its findings may not be generalisable. The instrument used was a pen-and-paper test; it did not replicate the real-world interactions that learners would experience in language processing. In real time, they would hear the interlocutors' utterances with varied intonation patterns and tones of voice, and process and produce their utterances under instant language processing pressure, while judging and decoding contextual clues using their pragmatic knowledge. In addition, the participants read situational descriptions and gave answers to multiple-choice questions, so they were more dependent on reading skills than on speaking and listening skills. The implicature test contained only 20 items-Garcia (2004) included 48 items in her study and Taguchi (2005) employed 38 items-so my questionnaire may have tested learners' pragmatic knowledge to a lesser degree than previous research. Triangulation could be employed in future studies, using retrospective interviews with participants to learn why they chose particular answers in the test. In addition, my findings could be tested and validated by future researchers with larger participant numbers, giving more power to discriminate between group characteristics.

\section{CONCLUSIONS}

This research was designed to examine a pragmalinguistic component — conversational implicature - that is relatively underrepresented in the ILP literature. The purpose of the study was to determine whether English L2 learners' ability to interpret conversational implicature differs when they are from different EAL contexts. The test items were designed using implied meanings appropriate to workplace interactions. Statistical analysis showed that the workplace participants' comprehension of implicature was significantly better than that of their learning context counterparts, and that this was due to their higher proficiency and (to a lesser extent) length of stay, rather than to workplace exposure. In addition, my study showed that formulaic implicatures are more difficult to understand than idiosyncratic implicatures. In the idiosyncratic category the most difficult item group was the larger socio-cultural group; in the formulaic category, the irony and indirect criticism groups were most difficult. Learners can benefit from mastering these groups of implicature through more socio-cultural awareness and interaction. Some inter-cultural training may also be useful for them.

The outcomes of this study will contribute to English language and intercultural policy making; ESL teacher professional development and standardisation; the inclusion of pragmatic components in Australian EAL curriculum design; and lesson planning to help address this vital pragmalinguistic element in English language learning. This work also makes a useful contribution to the ILP literature.

\section{ACKNOWLEDGEMENTS}

I would like to thank Dr. Carsten Roever who supervised my MA thesis at the University of Melbourne. I am grateful to the participants of this study, and my friends and colleagues, who helped me collecting data for this study. My special thanks and heartfelt gratitude go to my partner - Shamim Ahmed and my three daughters - Audrey, Cobie and Isla - for their genuine interest in my well-being, and for being tolerant and understanding about my workload at the time of this study.

\section{REFERENCES}

[1] Aitken, K. G. (1977). Using cloze procedure as an overall language proficiency test. TESOL Quarterly, 11, 59-67 
[2] Bardovi-Harlig, K., \& Dörnyei, Z. (1998). Do language learners recognise pragmatic violations? Pragmatic versus grammatical awareness in instructed L2 learning. TESOL Quarterly, 32, 233-259

[3] Bardovi - Harlig, K., \& Hartford, B. S. (1990). Congruence in native and nonnative conversations: status balance in the academic advising session. Language Learning, 40(4), 467-501.

[4] Bardovi-Harlig, K., \& Hartford, B. S. (1993). Learning the rules of academic talk: a longitudinal study of pragmatic development. Studies in Second Language Acquisition, 15, 279-304.

[5] Bardovi-Harlig, K., \& Hartford, B. S. (1996). Input in an institutional setting. Studies in second language acquisition, 18(2), 171-188.

[6] Brown, P., \& Levinson, S. D. (1987). Politeness: some universals in language usage. Cambridge University Press: Cambridge.

[7] Bouton, L. F. (1988). A cross - cultural study of ability to interpret implicatures in English. World Englishes, 7(2), 183-196.

[8] Bouton, L. F. (1992). The interpretation of implicature in English by NNS: does it come automatically without being explicitly taught. In L. F. Bouton \& Y. Kachru (Eds.), Pragmatics and language learning (pp. 53-65). Urbana-Champaign, IL: University of Illinois.

[9] Bouton, L. F. (1994a). Conversational implicature in the second language: learned slowly when not deliberately taught. Journal of Pragmatics, 22, 157-67.

[10] Bouton, L. F. (1994b). Can non-native speakers' skill in interpreting implicature in American English be improved through explicit instruction? A pilot study. In Bouton, L.F. (Ed.), Pragmatics and language learning (pp. 88-109). Urbana, IL: University of Illinois.

[11] Bouton, L. F. (1999). The amenability of implicature to focused classroom instruction. Paper presented at TESOL 1999, New York.

[12] Dufon, M. A. (2006). The socialization of taste during study abroad in Indonesia. In M. A. Dufon \& E. Churchill (Eds.), Language learners in study abroad contexts (pp. 91-119). Clevedon: Multilingual Matters.

[13] Garcia, P. (2004). Pragmatic Comprehension of High and Low Level Language Learners. TESL-EJ, 8(2), 1-12.

[14] Grice, P. (1975). Logic and conversation. In P. Cole \& J. Morgan (Eds.), Syntax and semantics (pp. 41-58). Academic Press: New York, NY

[15] Grieve, A. (2010). Adolescent identity and pragmatic marker acquisition in a study abroad context (Doctoral dissertation). Retrieved from Minerva Access: (https://minerva-access.unimelb.edu.au/handle/11343/36061).

[16] Hassall, T. J. (1997). Requests by Australian learners of Indonesian (Unpublished doctoral dissertation). Australian National University: Canberra.

[17] Hill, T. (1997). The development of pragmatic competence in an EFL context (Unpublished doctoral dissertation). Temple University Japan, Tokyo.

[18] Horn, L. R., \& Ward, G. L. (Eds.). (2004). The handbook of pragmatics (p. 3). Oxford: Blackwell.

[19] Kanagy, R., \& Igarashi, K. (1997). Acquisition of pragmatic competence in a Japanese immersion kindergarten. In L. Bouton (ed.), Pragmatics and language learning (pp. 243-265). Urbana, IL: University of Illinois.

[20] Kasper, G. (1997). Can pragmatic competence be taught? Honolulu: University of Hawai'i, Second Language Teaching \& Curriculum Center. Retrieved from http://www.nflrc.hawaii.edu/NetWorks/NW06/.

[21] Kasper, G., \& Rose, K. (2002). Pragmatic development in a second language. Malden, MA: Blackwell.

[22] Kasper, G., \& Röver, C. (2005). Pragmatics in second language learning. In E. Hinkel (Ed.), Handbook of research in second language teaching and learning (pp. 317-34). Mahwah, NJ: Lawrence Erlbaum.

[23] Leech, G. (1983). Principles of pragmatics. London: Longman.

[24] Matsumura, S. (2001). Learning the rules for offering advice: a quantitative approach to second language socialization. Language Learning, 51(4), 635-679.

[25] Matsumura, S. (2003). Modelling the relationships among interlanguage pragmatic development, L2 proficiency, and exposure to L2. Applied Linguistics, 24(4), 465-491.

[26] Murray, J. (2011). Do Bears Fly? Revisiting Conversational Implicature in Instructional Pragmatics. TESL-EJ, 15(2), 1-30.

[27] Nigar, N. (2015). Activities of indirect communications lesson for adult ESL students at advanced level. Retrieved from https://bit.ly/32jCRy3.

[28] Niezgoda, K., \& Röver, C. (2001). Pragmatic and grammatical awareness: a function of learning environment? In K. R. Rose \& G. Kasper (Eds.), Pragmatics in language teaching (pp. 63-79). Cambridge University Press: New York.

[29] Oiler Jr, J. W., \& Conrad, C. A. (1971). The cloze technique and ESL proficiency. Language Learning, 21(2), 183-194.

[30] Olshtain, E., \& Blum-Kulka, S. (1985). Crosscultural pragmatics and the testing of communicative competence. Language testing, 2(1), 16-30.

[31] Omar, A. (1991). How learners greet in Kiswahili: a cross-sectional survey. In L. Bouton \& Y. Kachru (Eds.), Pragmatics and language learning (pp. 59-73). University of Illinois: Urbana, IL.

[32] Osuka, N. (2017). Development of pragmatic routines by Japanese learners in a study abroad context. In Current issues in intercultural pragmatics (pp. 275-296). John Benjamins Amsterdam/New York.

[33] Rose, K. R. (2009). Interlanguage pragmatic development in Hong Kong, phase 2. Journal of Pragmatics, 41(11), $2345-2364$.

[34] Röver, C. (2005a). Testing ESL pragmatics. Tübingen: Gunter Narr.

[35] Röver, C. (2006). Testing ESL pragmatics: Development and validation of a web-based assessment battery. Peter Lang: Frankfrut.

[36] Röver, C. (2006). Validation of a web-based test of ESL pragmalinguistics. Language Testing, 23(2), 229-256.

[37] Röver, C. (2011). What learners get for free: learning of routine formulae in ESL and EFL environments. ELT Journal, 66(1), $10-21$.

[38] Röver, C. (2013). Testing implicature under operational conditions. In S. J. Ross \& G. Kasper (Eds.), Assessing second language pragmatics (pp. 43-64).

[39] Roever, C., \& McNamara, T. (2006). Language testing: The social dimension. International Journal of Applied Linguistics, 16(2), 242-258. 
[40] Schmidt, R. (2001). Attention. In P. Robinson (Ed.), Cognition and second language instruction (pp. 3-32). Cambridge: Cambridge University Press.

[41] Shively, R. L. (2011). L2 pragmatic development in study abroad: A longitudinal study of Spanish service encounters. Journal of Pragmatics, 43(6), 1818-1835.

[42] Sperber, D., \& Wilson, D. (1995). Relevance: communication and cognition (2nd ed.). Cambridge: Cambridge University Press.

[43] Thomas, J. (1983). Cross-cultural pragmatic failure. Applied Linguistics, 4, 91-112.

[44] Taguchi, N. (2002). An application of relevance theory to the analysis of L2 interpretation processes: the comprehension of indirect replies. International Review of Applied Linguistics in Language Teaching, 40(2), 151-176.

[45] Taguchi, N. (2005). Comprehending implied meaning in English as a foreign language. The Modern Language Journal, 89(iv), 543-562.

[46] Taguchi, N. (2007). Development of speed and accuracy in pragmatic comprehension in English as a foreign language. TESOL Quarterly, 41(2), 313-338.

[47] Taguchi, N. (2008a). Pragmatic comprehension in Japanese as a foreign language. Modern Language Journal, $92,558576$.

[48] Taguchi, N. (2008b). The role of learning environment in the development of pragmatic comprehension: A comparison of gains between EFL and ESL learners. Studies in Second Language Acquisition, 30, 423-452.

[49] Taguchi, N. (2011). The effect of L2 proficiency and study-abroad experience in pragmatic comprehension. Language Learning, 61, 904-939.

[50] Trosborg, A. (1995). Interlanguage pragmatics: requests, complaints, and apologies. Berlin: Mouton de Gruyter.

[51] Yamanaka, J. (2003). Effects of proficiency and length of residence on the pragmatic comprehension of Japanese learners. Second Language Studies, 22(1), 107-175.

[52] Yamashita, S. A. Y. O. K. O. (2008). Investigating interlanguage pragmatic ability: What are we testing. Investigating Pragmatics in Foreign Language Learning, Teaching and Testing, 30, 201.

[53] Yamashita, S. A. Y. O. K. O. (2008). Investigating interlanguage pragmatic ability: What are we testing. In E. A. Soler \& A. Martínez-Flor (Ed) Investigating Pragmatics in Foreign Language Learning, Teaching and Testing (pp. 201 - 223). Bristol: Multi-lingual Matters.

Nashid Nigar is an academic skills adviser at the University of Melbourne, Australia. Her academic and work experience ranges multiple disciplines and skills areas. A few of her research interests are English Language Teaching, academic literacy/learning, career development, teachers' professional identity, inter-cultural interactions and educations, online/blended learning, pragmatics and sociolinguistics. She has taught English and worked as a teaching academic, and academic skills adviser in universities and other tertiary institutes for more than 15 years across various sectors in Australia and abroad. 